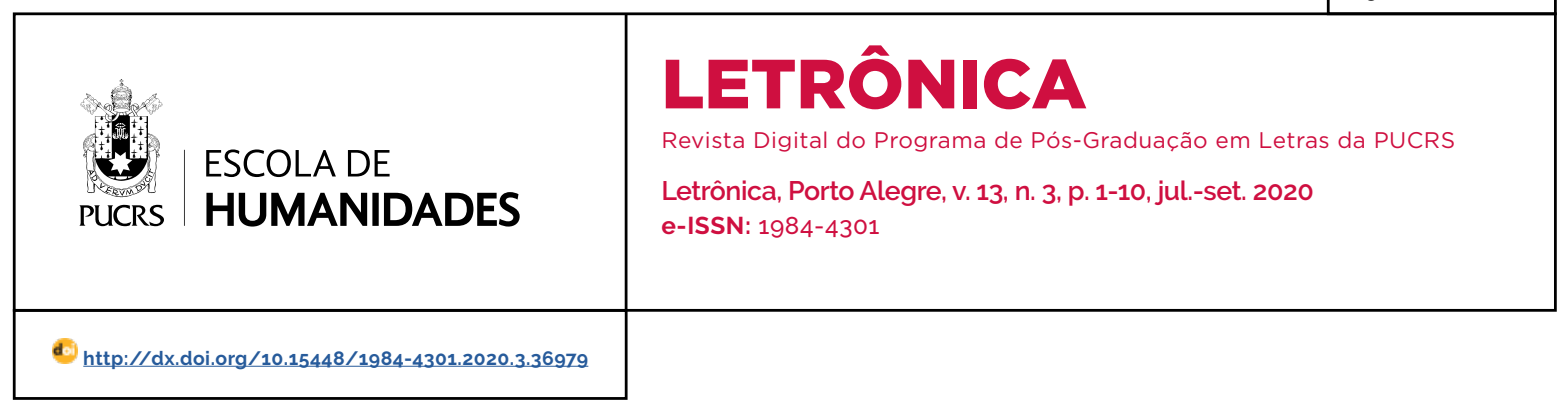

\title{
A periferia na literatura brasileira contemporânea, um exercício de alteridade
}

\author{
The Periphery in Contemporary Brazilian Literature, an Exercise of Otherness
}

\section{Maria Tereza Amodeo ${ }^{1}$}

orcid.org/0000-0002-5039-4365 mtamodeo@pucrs.br

Recebido em: 29 jan. 2020 Aprovado em: 16 abr. 2020. Publicado em: 30 out. 2020.
Resumo: O artigo analisa formas de tratamento dos temas da realidade marginal/periférica presentes em contos e poema brasileiros contemporâneos, a partir da perspectiva das figuras "ex-cêntricas" da sociedade (HUTCHEON, 1998), silenciadas historicamente, relegadas à margem e que circulam em torno daquele tipo ideal de homem realizado, nomeado como "Senhor Todo Mundo" (LANDOWSKI, 2002). Concebidas frequentemente por imagens estereotípicas (BHABHA, 1999), que possuem efeito de verdade, embora estrábicas e redutoras, tais figuras vivem em um "exilio ontológico" (OUELLET, 2013), que se relaciona à "ausência ou estreitamento de seu espaço de existência ou de seu campo de pertencimento". Ao se descartarem critérios de ordem de valor, com nítida tendência hierarquizante, rejeitando-se posições dicotômicas, maniqueístas, propõe-se avaliar como a literatura pode promover/ou não o exercício da alteridade ao desconstruir/ratificar estereótipos geralmente associados a tais figuras. Palavras-chaves: Alteridade. Centro. Periferia. Estereótipo. Contemporaneidade.

Abstract: The article analyzes ways of dealing with the themes of marginal/ peripheral reality present in contemporary Brazilian short stories and poems, from the perspective of the "ex-centric" figures of society (HUTCHEON, 1998), historically silenced, relegated to the margins and circulating around that ideal type of accomplished man, named "Lord Everybody" (LANDOWSKI, 2002). Often conceived by stereotypical images (BHABHA, 1999), which have a real effect, although squinting and reducing, these figures live in an "ontological exile" (OUELLET, 2013), which is related to the "absence or narrowing of their space of existence or their field of belonging". By discarding criteria of order of value, with a clear hierarchical tendency, rejecting dichotomous and Manichean positions, it is proposed to evaluate how literature can promote / or not the exercise of otherness by deconstructing / ratifying stereotypes generally associated with such figures. Keywords: Otherness. Center. Periphery. Stereotype. Contemporaneity. 


\section{Introdução}

Para Antonio Candido O cortiço, de Aluizio de Azevedo, muito mais do que a história de uma habitação coletiva do Rio de Janeiro, é a narrativa do próprio Pais, que sujeita "o povo humilde, que era então composto em grande parte de negros, mestiços e imigrantes pobres", à exploração econômica do capital estrangeiro (2004, p. 74). A descrição do crítico sobre o Pais, ao tempo da antológica obra realista, parece atualissima. Hoje, os descendentes daqueles negros, mestiços, imigrantes pobres, vivem ainda situações de desigualdade que, mais do que tematizadas pela literatura e pelas novas formas culturais que surgem na contemporaneidade, são desmascaradas, escancaradas por elas, provocando toda a sorte de reações.

Candido qualifica de "franqueza realista" o estilo de Azevedo ao tratar dessa parte da população brasileira no seu próprio espaço, rejeitando, assim, a "tendência transfiguradora da nossa literatura" (2004, p. 74), aquela que, ao bom estilo romântico, embelezava as idiossincrasias do País que se desenhava. Hoje, a realidade é literatura, o que efetivamente mobiliza leitores e criticos.

É fato, pois, que, desde o século XIX, a literatura brasileira tem produzido modos de representação de espaços marcados pela pobreza, principalmente por autores que, sensibilizados por essa realidade ou, revoltados com ela, a veem de fora, por vezes, de maneiras estereotipadas. Mais recentemente, autores oriundos desses contextos, ou extremamente ligados a eles, constroem formas originais, legítimas e, também, polêmicas, que expressam uma relação assumida de pertencimento a suas origens. É nessa medida que o presente artigo propõe um olhar sobre algumas das formas que a realidade marginal/periférica assume na literatura brasileira contemporânea.

Nessa medida, elege-se um aporte teórico que parte da percepção das figuras "ex-cêntricas" da sociedade, na acepção da crítica literária canadense Linda Hutcheon (1998), aquelas que foram, ao longo da história, relegadas à margem, circulando em torno daquilo que simbolicamente se convencionou denominar como o ideal dentro da sociedade, que representa o grupo dominante, a que o semiólogo francês Erick Landowski (2002) cunhou como o "Senhor Todo Mundo". Esse é o modelo a ser seguido, que provoca a exclusão daqueles que vivem em áreas marginalizadas das grandes cidades.

"Favela", "quebrada", "perifa", "comunidade" etc.: são várias as possibilidades de nomear as áreas periféricas das cidades brasileiras, intensamente identificadas como redutos do crime organizado, onde vive, também, a classe trabalhadora, no sentido mais amplo que se possa conceber, incluindo ocupações mais ou menos ou nada formais, que convivem com a pobreza sistêmica. Marginalizada e/ou ignorada não apenas pelos órgãos públicos, mas também pela própria sociedade, essa camada da população convive com violência, morte, desastres, frustração, miséria e fome, ao mesmo tempo em que desenvolve ações de luta, resistência, organização, expressando suas próprias e legitimas modalidades culturais (REYES, 2013).

O conceito de "dialética da marginalidade", como bem pontua João César de Castro Rocha, no seu paradigmático artigo de 2006, ${ }^{2}$ fundamenta-se na superação "do lugar de desigualdade, mediante o confronto, em lugar da conciliação" (presente no conceito de "dialética da malandragem" de Candido) em relação à "exposição da violência, em lugar do seu ocultamento" (2006, p. 23).

\section{A literatura em questão}

A literatura contemporânea pode surpreender, desacomodar, transgredir, quando se organiza a partir dessa perspectiva, como ocorre no conto "O Ônibus Branco", de Ferréz.

Entrei, já estava lotado, não havia notado a semelhança dos passageiros, estava esgotado.

Não sabia mais por onde correr, os dois inimigos atrás de mim não acertaram os tiros, estou intacto fora o cansaço.

Nem vi de onde eles sairam [...].

Olhei para o lado e vi o meu parceirinho, não acreditei, Marquinhos ali do meu lado.

E aí, parceiro, com vai? 
Tamo indo, mó saudade Nal, me dá um abraço aqui.

[...] por onde tinha andado?

Ah! Desde aquele dia da pizzaria que meu anjo da guarda se distraiu eu fiquei por aqui, tô nesse ônibus, tô junto com outros, olha lá o China, já tá tentando abrir a porta, o motorista fica que fica louco.

Pode crê! Oh, China...

E aí, Ferréz?

Meu, como vai você, cara? (2006, p. 49).

O conto, publicado em Ninguém é inocente em São Paulo, primeiro livro de contos de Ferréz, como em uma enxurrada de realidade, arremessa o leitor para dentro de um ônibus de linha, junto com o narrador-protagonista, que foge de tiros disparados por desconhecidos. O texto, em especial o diálogo predominante - a exceção nos dos primeiros e dos dois últimos parágrafos ${ }^{3}$-. traz a linguagem própria dos moradores das comunidades periféricas.

A narrativa cria uma expectativa de que se trata de uma experiência real vivida pelo próprio autor, uma vez que Ferréz é identificado por um dos personagens; além disso é o próprio narrador. o que reforça o tom de relato pessoal. O autor, morador do Capão Redondo, região periférica de São Paulo, desempenhou, na juventude, atividades profissionais pouco valorizadas na pirâmide social. ${ }^{4}$ Mesmo que o leitor ignore o fato de que Ferréz poderia realmente ter convivido com individuos reais como os personagens do conto, a estratégia imprime tom de veracidade ao narrado, associando autor-narrador-personagem ao universo marginalizado/periférico; ao mesmo tempo, reconfigurando os limites dessas categorias narrativas.

Outros dados do real compõem a narrativa, entretanto ela se constrói como ficção, na medida em que se organiza a partir de uma série de estratégias articuladas. O protagonista surpreende-se com "a semelhança dos passageiros"; vai reconhecendo, entre eles, amigos que não via há muito tempo; ouve de um que está ali porque "o anjo da guarda se distraiu" e, também, ao final, de outro: "esse ônibus, por enquanto, não tem destino pra você" (2006, p. 49) - referências, dentre outras, que ficam suspensas, sem uma explicação clara, como se espera de uma narrativa puramente realista, mas que estão em conexão na economia geral do conto.

Associadas ao título do conto, infere-se que o autor efetivamente pode ter conjugado experiências e, possivelmente, referências da sua própria realidade para construir uma narrativa ficcional, que possui ligações com o espiritismo, no que se refere ao entendimento da morte. Essa possibilidade de plano de entendimento contribui para configurar o caráter literário da narrativa, que pode, também, ser compreendida como um relato de tom fantástico, na medida em que reúne, no universo da diegese, figuras reais, que parecem já ter morrido.

Parceiros de Ferréz na realidade ou na ficção? Importa que os personagens do conto não são bandidos condenados/mortos, sendo julgados por seus feitos a partir dos códigos legisladores da sociedade (talvez pela lei divina). São individuos em transição, que circulam na cidade dentro de um ônibus, sem saberem por quanto tempo ou que destino lhes aguarda. Não são analisados, descritos ou justificados. Não aparecem em ação, matando ou roubando: estão apenas em trânsito, "vivendo" como possivel, lidando com o que a vida/morte lhes reserva - de forma metafórica como acontece na realidade das periferias das grandes cidades. O conto tem elementos para mobilizar o leitor - seja ele oriundo da periferia ou não -, uma vez que faz ver individuos periféricos em um contexto imagético habilmente tecido pelo autor, que remete à realidade da periferia, sem imprimir qualquer tom pedagógico ou reivindicatório da classe desprivilegiada.

O conto de Ferréz parece materializar o que o crítico literário Karl Erick Schollhammer afirma em Ficção brasileira contemporânea (2009), em relação ao que denomina de novo projeto/vontade, que surge desde o final do século $X X$, que,

\footnotetext{
3 "Desci, andei por uma rua escura muito tempo, até achar uma claridade, parei e me dei conta de que a maior alegria da minha vida vai ser quando meu filho nascer, fechei os olhos e abracei todos os meus amigos que se foram./ Cheguei em casa e ainda não consegui parar de chorar, pois sei que o ônibus vai continuar tendo novos passageiros, sempre, sempre, sempre.!" (FERRÉZ, 2006, p. 51).

4 Foi vendedor ambulante de vassouras, balconista em bares e padarias, auxiliar-geral de construção, arquivista e chapeiro em rede de fast-food. Disponivel em: http://enciclopedia.itaucultural.org.br/pessoa280342/ferrez. Acesso em: 11 de outubro de 2019.
} 
sem se constituir em um revival das técnicas de verossimilhança descritiva de objetividade narrativa do realismo do século XIX, tende a retratar a realidade atual da sociedade brasileira "pelos pontos de vista marginais ou periféricos" (2009, p. 53). Assim é que não se pode falar em representação ou mimese, no sentido clássico dos termos.

O novo realismo se expressa pela vontade de relacionar a literatura e a arte com a realidade social e cultural da qual emerge, incorporando essa realidade esteticamente dentro da obra e situando a própria produção artística como força transformadora. [...] Estamos falando de um tipo de realismo que conjuga as ambições de ser "referencial", sem necessariamente ser representativo, e ser, simultaneamente, "engajado", sem necessariamente subscrever nenhum programa politico ou pretender transmitir de forma coercitiva conteúdos ideológicos prévios (SCHOLLHAMMER, 2009, p. 54).

O conto de Ferréz pode, sim, ser entendido como uma incorporação estética da realidade, entretanto não é a este tipo de literatura que o crítico faz referência. Aponta os autores da Geração oo, dentre eles Luiz Ruffato, Marcelino Freire, Nelson de Oliveira, Marçal Aquino, como os responsáveis pela inovação estética no tratamento da realidade. Trata-se de autores que, mesmo produzindo um novo e importante tipo de realismo, não são oriundos das comunidades periféricas. O crítico, portanto, parece não reconhecer qualidade estética em trabalhos produzidos no âmbito mesmo da periferia.

Schollhammer ressalta o caráter comercial da "literatura marginal" e atribui à superexposição e à espetacularização da realidade promovida pelas midias na atualidade o "fascínio em torno de vozes e depoimentos de uma realidade excluida" (2009, p. 98). ${ }^{5}$ Segundo o crítico, tais vozes surgem sem qualquer compromisso com a qualidade estética.

[...] já não é mais possivel avaliar o engajamento ou o compromisso com a realidade pela opção temática e nem pelos conteúdos escolhidos, uma vez que a realidade marginal e periférica foi há muito incorporada pelo desejo espetacular, pela linguagem melodramática e sentimental, e pela aceitação, por parte da crítica, de uma linguagem neorrealista simples, que se canonizou e agora se reproduz dentro do documentarismo, do cinema e da prosa ficcional mainstream (SCHOLLHAMMER, 2009, p. 54).

A vinculação a uma clara posição política dos autores que produzem sob a etiqueta da literatura marginal ou que, de algum modo possam estar à margem de um centro estabelecido, fragilizam, ainda, os conceitos tradicionais do que se convencionou considerar esteticamente literário. Nessa medida, cabe a utilização de outras ferramentas, "que não se baseiem apenas nos valores estéticos das obras", conforme refere o crítico brasileiro Paulo Roberto Tonani do Patrocínio (2013), mas que permitam uma reflexão mais sintonizada com as especificidades contemporâneas de dizer/expressar/criar.

Rejeitando-se posições dicotômicas, maniqueistas que consideram, por exemplo, um desafio "encontrar experiências formais adequadas" (SCHOLLHAMMER, 2009, p. 54) aos temas relacionados à realidade marginal/periférica, é preciso descartar critérios de ordem de valor, com nítida tendência hierarquizante. O estereótipo fundamenta esse tipo de abordagem, constituindo-se em importante estratégia discursiva.

Conforme postula o crítico cultural indiano Homi Bhabha (1999), o estereótipo atua como "esquema epidérmico", como um conhecimento aparentemente espontâneo, incorporado como algo natural. A discriminação promovida pelas modalidades estereotípicas atua de forma limitadora, reduzindo a realidade a proposições binárias, excludentes, estratificando posições, isolando indivíduos e grupos. É a repetibilidade que garante o efeito de verdade, de probabilidade, de predictabilidade, pelo excesso, sem provas (BHABHA, 1999).

Impressiona como, apesar da longa reflexão empreendida pelos teóricos pós-colonialistas ao longo do século XX, as mentes, atitudes e criações dos indivíduos contemporâneos ainda estejam tão impregnadas das formas de subjetivação da "fórmula colonialista" (BHABHA, 1999), que atribui poder e importância a uns em

5 Schollhammer, inclusive, menciona Ninguém é inocente em São Paulo como exemplo desse fascínio, em uma clara critica à literatura de Ferréz. 
detrimento de outros, que percebe as relações em uma perspectiva dual, criando-se e perpetuando-se estereótipos de variada ordem, o que impede que se construam caminhos menos excludentes, ortodoxos, dogmáticos de entendimento, de convívio, de expressão.

Esse processo, para ser desmobilizado, exige uma reação teórica forte, sem determinismos/ funcionalismos, questionando posições dogmáticas/moralistas como intervenção, promovendo um deslocando do imediato reconhecimento das imagens estereotípicas pelo reconhecimento da presença da diferença. A literatura - como outras artes - materializa essa função, podendo ratificar ou desconstruir estereótipos, neste último caso, promovendo o exercício de alteridade.

A letra da canção de Vinícius de Moraes e Antonio Carlos Jobim da década de 1960 já insinuava questões importantes para a reflexão aqui proposta:

\section{O morro não tem vez \\ E o que ele fez já foi demais \\ Mas olhem bem vocês \\ Quando derem vez ao morro \\ Toda a cidade vai cantar. ${ }^{6}$}

O ritmo melodioso do samba pode até suavizar o caráter político que está presente nessas palavras, pois, ao falar de vez, deixa entrever a ideia de voz, de fala, de participação política dos moradores da periferia por meio da arte. Os dois jovens compositores - brancos, de classe média, com educação universitária -, produziram a canção que, já naquela época, vaticinava a participação político/cultural daqueles que estão à margem da sociedade. Alento para os do morro? Sensibilidade dos jovens músicos? Sem dúvida, os compositores são capazes de reconhecer e expressar as potencialidades daqueles que vivem no morro parte periférica da cidade. A canção, entretanto, expressa o olhar dos de fora sobre os de dentro das comunidades periféricas, olhar que é dirigido para seus pares: "Mas olhem bem vocês". Essa perspectiva é uma forma de idealização dessas figuras da sociedade que Linda Hutcheon (1998) denomina de "ex-cêntricas", por serem aquelas silenciadas historicamente, relegadas à margem.

$\mathrm{Na}$ discussão em voga ainda na década de 1980 acerca do pós-modernismo, ${ }^{7}$ Hutcheon se refere ao desafio à noção de centro, à "reordenação excêntrica geral da cultura" (1998, p. 91), que envolve "grupos definidos por diferença de raça, sexo, preferências sexuais, identidade étnica, status pátrio e classe" (1998, p. 89). No bojo dessa discussão, situa-se o entendimento da alteridade, que, espantosamente, nos dias de hoje, parece cada vez mais ser compreendida como uma ameaça; certamente uma ameaça aos essencialismos que negam as especificidades, particularidades de ser um ex-cêntrico, alguém visto em uma perspectiva estereotipada na sociedade.

O foco na socialização e na convivência pela diferença permite perceber as relações que se estabelecem no mundo, vislumbrando a arte como força transformadora. As expressões literárias que, de algum modo, promovem o exercicio de alteridade exigem uma abordagem teórica sintonizada com as emergências da contemporaneidade, que percebe a arte - a literatura - em conexão com a realidade, expressando as idiossincrasias, as especificidades, as diferenças das identidades ex-cêntricas. O exame de algumas expressões literárias brasileiras, dentre a vasta produção das duas décadas do século XXI no país, evidencia formas diferenciadas de tratamento dos estereótipos, desconstruindo-os, insinuando tentativas para tal, ou, ainda, ratificando-os.

\footnotetext{
Mãe, eu quero ser Xuxa. Mas minha filha. Eu quero ser Xuxa. A menina não tem nem nove anos, fica tagarelando com as bonecas. Com as pedras do Morro. Eu quero ser Xuxa. Mas minha filha.

A mãe ia fazer um book, como? [...]

A mãe já vivia da ajuda do povo. Mas tinha de levar a menina ao cinema. [...]

Eu quero ser Xuxa. Eu quero ser Xuxa. Eu quero ser Xuxa. Um dia eu esfolo essa condenada. Deus me perdoe. Essa danada da Xuxa. Dou
} 
uma surra nela para ela tomar jeito. Fazer isso com filha de pobre. Que horror!

A mãe mal chegou do trabalho a menina já falou. Que a Xuxa vem esse final de semana. [...]

A mãe tinha de faltar ao trabalho de novo. [...]

Pendurou a menina nas costas e enfrentou o calor. E o empurra-empurrão. E também gritou para ver se a Xuxa ouvia: Xuxa, Xuxa, Xuxa. Pelo amor de Deus! Faz essa menina calar a boca. Diz pra ela pensar em outra coisa, sonhar com os pés no chão.

Quando ela vai ser, assim como você, um dia? A Rainha dos Baixinhos nossa Rainha da Bateria, sei não, sei lá (FREIRE, 2005, p. 73-75).

Em tom engraçado, irônico e, até, dramático, o conto "Nossa Rainha", de Marcelino Freire traz a figura real de Xuxa, a ex-apresentadora de programas infantis da Rede Globo de Televisão, que foi idolatrada, imitada e considerada um mito pelas crianças de todas as classes sociais principalmente das últimas décadas do século $\mathrm{XX}$, denominada "a rainha dos baixinhos".

A trajetória de Xuxa é um perfeito exemplo das disfunções da televisão brasileira, um vigoroso e carismático movimento que merece ser objeto de estudo sobre as influências midiáticas produzidas nos últimos anos. Fama, publicidade, mercado, comportamento, imagem, sexualização precoce, infantilização, privacidade, discurso - todos esses elementos costuram a anatomia de um dos fenômenos comunicacionais brasileiros mais significativos das últimas duas décadas (JUNIOR, 2001, p. 3).

Referida como a "a rainha loura dos colonizados" pelo autor do artigo em questão, Xuxa efetivamente frequentou os lares brasileiros de norte a sul, influenciando comportamentos e promovendo um gigantesco mercado de produtos. A narrativa de Marcelino Freire, publicada em Contos negreiros, de 2005, traz como personagens uma mãe e sua filha que, pela proposta geral do livro, depreende-se que sejam negras e, conforme mencionado no conto, pobres: "Fazer isso com filha de pobre" (2005, p. 74).

Narrado em terceira pessoa, o conto focaliza o ponto de vista da mãe, desesperada com o fato de a menina querer ser Xuxa, o que a obriga a gastar o que não tem para levá-la ao cinema ou aonde e quando a apresentadora se apresentar. O uso do discurso indireto livre contribui para intensificar o tom de oralidade presente em toda a narrativa. Outras referências à realidade brasileira, principalmente do contexto periférico, mas não exclusivamente, em especial à época de produção do conto, aproximam a narrativa do gênero crônica, o que não desfigura o seu caráter literário, por se tratar de uma narrativa que provoca um olhar para a realidade, jocoso, talvez, mas reflexivo, critico, sensivel.

A repetição reiterada da frase, "Eu quero ser Xuxa.", como um refrão, intensifica a irritação da mãe e, a cada menção, reitera o desejo da menina de se identificar com alguém tão diferente dela: branca, loira, rica. Na sua aparente leveza, a narrativa remete a um tipo de experiência de individuos marginalizados, alijados da participação política na sociedade: a menina não quer simplesmente se parecer com Xuxa, ela quer ser Xuxa, embora isso não seja possivel.

O conto de Marcelino Freire relaciona-se à ideia de "ex-cêntrico, o off-centro: inevitavelmente identificado com o centro ao qual aspira, mas que lhe é negado", conforme Hutcheon (1998, p. 88) - conceito que dialoga diretamente com o de "Sr. Todo Mundo", do sociólogo e semiólogo francês Eric Landowski (2002), que analisa os principios de uma dinâmica identitária, salientando que "todo meio produz efetivamente seu próprio tipo ideal de homem 'realizado'" (2002, p. 39). Seria o tipo ideal localmente concebido, em torno do qual os outros - aqueles que não se enquadram naquilo que caracteriza este "Senhor Todo Mundo" - transitam, circulam, com ele estabelecendo diferentes relações, mas dificilmente conseguindo se igualar (LANDOWSKI, 2002, p. 39), "como um Sol no céu dos Estados e impérios da Lua [...] agindo por sua presença no próprio centro do sistema" (2002, p. 38). O homem, branco, heterossexual, culto, urbano em geral assume este papel idealizante, exemplar.

A menina do conto vê em Xuxa o ideal a ser atingido. Todo o contexto capitalista, que costuma estimular os filmes, os shows, a compra de brinquedos e vestimentas da Xuxa, cria a ilusão de aproximação, de que um dia será como ela. 
Em que medida, de que modo, o sistema de estereótipos identitários fixado pelo grupo "de referência" (ou aquele que se considera como tal) deverá servir, também, de referência a eles, que esse "Um" designa como seu "Outro"? Por um lado entendemos que um grupo social que goze localmente de uma posição econômica cultural ou política dominante, e que tenha uma espécie de auto-imagem idealizada, tenda a definir negativamente a alteridade daqueles que ele não reconhece como sendo seus, e isso na proporção daquilo que constitui, de seu ponto de vista, seu grau de não conformidade em relação à normalidade que ele crê encarnar. Mas se invertermos a perspectiva, por que aqueles que são rotulados e, ao mesmo tempo rejeitados dessa maneira interiorizariam precisamente a mesma norma? É preciso que eles se considerem o negativo do grupo que os discrimina? (LANDOWSKI, 2002, p. 33).

Criança, negra, pobre, periférica, a menina é o oposto de Xuxa, mas internaliza os seus valores e a aparente imagem idealizada, rejeitando, assim, a sua própria identidade. Ao querer ser a outra, a menina reforça a sua subalternidade: incorpora a vestimenta, as atitudes e até a fala de Xuxa, em um processo que é analisado pelo crítico canadense Patrick Imbert, como "mimese da apropriação", termo que toma emprestado do francês René Girard:

A mimese da apropriação tem por objetivo controlar o objeto desejado, que é representado pelo que é externo ao discurso do homem. No contexto religioso, o objeto externo é a palavra de Deus. Num estado laico, é representado pelos fatos científicos e pelos valores culturais. Aquilo que é externo ao discurso está integrado ao mundo dos homens pelo caminho da mimese, no sentido platônico do termo, isto é, por um modo essencialista e dualista de representar a realidade (2008, p. 21).

A menina do conto e Xuxa estão em posições irreconciliáveis na sociedade. A primeira, ao imitar os gestos da segunda, pensa poder alcançar o seu objeto de desejo - ser Xuxa - e, com ele, o poder, a superioridade, o glamour que julga habitarem a vida da apresentadora. Incorpora a máscara da outra - o seu discurso - como possibilidade de viver o impossivel, negando, assim, a sua própria identidade.

Reconhecer que o discurso do marginalizado pode estar ligado mimeticamente a uma forma de apropriação da posição daquele que vive em uma situação privilegiada cultural e/ou econômica, constitui-se, sem dúvida, em uma perspectiva de quem está nessa segunda posição e olha de fora para a realidade apresentada na narrativa em questão - no caso, Marcelino Freire. Entretanto, constitui-se em uma perspectiva legítima, que revela por parte do autor um exercício de alteridade, que se estende ao leitor. Embora, nesse sentido, seja legítima, coerente, poderia encontrar oposição do(a)s teórico(a) que reivindicam o lugar de fala (RIBEIRO, 2017), aqui tomado como o lugar de quem fala da periferia.

Sobre essa questão, cabe mencionar o crítico Patrocínio, para quem Marcelino Freire é uma possibilidade (2013), se considerado ao lado de autores como Ferréz, Allan Santos da Rosa e Sérgio Vaz, dentre aqueles que produzem os Escritos à margem, título de sua obra sobre "a presença de autores de periferia na cena literária brasileira" (subtítulo da mesma obra). Possibilidade porque "trilhou um percurso de produção que se assemelha aos autores da Literatura Marginal" e faz escolhas temáticas semelhantes às dos autores periféricos (2013, p. 211).

Mesmo admitindo que "tal proximidade fica restrita ao plano temático, à escolha do objeto a ser representado no exercício literário" (2013, p. 213), ao responder a posições que exigem a legitimidade do lugar de fala, Patrocínio afirma que "o jogo empreendido por Freire se baseia na constante tentativa de se colocar no lugar do Outro" (2013, p. 218), em especial na obra Contos negreiros, em que "a própria linguagem que o autor constrói possibilita que os personagens se expressem sem a oferta de uma voz exterior ao narrado" (2013, p. 219).

Diferentemente acontece no conto "Balaio", de Marçal Aquino, publicado em Eu sou favela (2015), coletânea organizada pela francesa Paula Anacaona ${ }^{8}$, que está ao lado de contos de autores como Alessandro Buzo, Ferréz, João Anzanello Carrascoza, Marçal Aquino, Marcelino Freire, Sa-

8 A obra, publicada no Brasil pela Editora Nós, foi primeiramente publicada, em 2011, na França pela Editora Anacaona, com o título Je suis favela. A editora Paula Anacaona é especializada em literatura brasileira, tendo já publicado obras clássicas, mas especialmente do que se convencionou chamar de "literatura marginal", segundo a editora. 
colinha, dentre outros. Na narrativa, dois homens entram em um bar em busca de um certo Tiãozinho, por "encomenda de um grandão da Zona Norte" (AQUINO, 2015, p. 15), enquanto o narrador e os amigos jogam truco. Ao perguntarem do motivo da busca, os dois homens respondem que não sabiam. O narrador continua:

Eu disse que, sem conhecer o motivo, ficava dificil.

Um deles comentou que talvez o grandão quisesse as informações para decidir algo positivo em favor do Tiãozinho. Tinha a pele cor de pastel cru. Parecia uma dessas pessoas que nunca comem carne.

O outro era preto. Três rugas no rosto: duas quando ria, ao redor da boca; a outra aparecia na testa, na hora em que ficava sério. Impossivel saber a idade dele.

O branco prosseguiu aventando: Quem sabe o Tiãozinho não está pra assumir uma posição importante com o homem?

O preto emendou: Pois é, e se ele estiver pra casar com a filha do homem? O Tiãozinho não seria capaz de um negócio desses?

O grandão é bicha?, eu perguntei.

O preto: Não, claro que não.

E o outro: Por quê?

Porque o Tiãozinho é capaz de qualquer coisa, eu disse. Inclusive de estar casando com esse grandão aí (AQUINO, 2015, p. 45).

Qual a relevância de mencionar a impossibilidade de definir a idade do preto, se a do outro nem é cogitada? Talvez porque seja comum, no Brasil, o comentário de que pessoas negras não mostram a idade? A informação não faz a menor diferença para a narrativa. E assim continua referindo os dois homens como o "preto" e o "branco", sem que haja qualquer relevância na história o fato de serem, respectivamente preto e branco. Supõe-se que, na intenção de propositalmente não identificar os personagens, porque deveriam ficar incógnitas por força da tarefa de que foram incumbidos, escolher a cor da pele para diferenciá-los é, no mínimo, desnecessário, o que provavelmente um escritor negro não faria.

Aqui o olhar é de fora, de quem conta uma história a partir de referências externas ao contexto da favela, da periferia. "Pedi a Josué que saísse e baixasse a porta do bar. Ele fez isso, depois de lançar uma expressão triste para o balcão e para as garrafas nas prateleiras" (2015, p. 47). A menção ao balcão e às garrafas nas prateleiras é logo seguida da cena final quando acontece um tiroteio, bem ao estilo de faroeste americano:

O tiroteio durou meio minuto, se tanto. Quando
reacendi as luzes, o preto estava com a ca-
beça tombada numa poça de sangue sobre
a mesa. O branco caira para trás, arrastando
junto sua cadeira. Eu me aproximei e notei
que, apesar de estar com um ferimento feio
acima do olho direito, ele ainda gemia. Mirei
na cabeça e puxei o gatilho, mas as balas do
revólver tinham acabado. Um dos rapazes me
empurrou para o lado e completou o serviço
(AQUINO, 2015, p. 45).

"Gostei da cena" (2015, p. 46), diz o narrador, ao se referir à ameaça que significava a presença dos policiais naquele bar. Essa é a perspectiva da narração: de quem conta uma história a partir do olhar externo, como se visse uma cena, pelo pitoresco, sem qualquer tipo de adensamento nas motivações das personagens, periféricas. A narrativa traz o mundo do crime, as brigas, as mortes, a inoperância da polícia - temas que encontram eco na realidade das periferias. Entretanto, são apresentados por meio de uma lente externa, que veicula estereótipos em relação ao negro, ao mundo do crime, como um pastiche dos filmes de faroeste, sem estabelecer qualquer sentido de outridade.

Assim, as relações entre centro e periferia e todos os conceitos que envolvem esse binômio, no que se refere especificamente aos contos da literatura brasileira contemporânea até aqui focalizados, devem ser entendidas como possibilidades do literário dos tempos que correm, não necessariamente da prosa literária. Embora muito aprioristicamente alguns entendam que sim, esta breve guinada para a poesia pode ilustrar a questão:

\section{POÉTICA DA DESISTÊNCIA}

Um poema (eu quero)

Desses que desautorizam,

Desses que nascem na chuva,

Param na curva

E desistem da rebelião.

Um poema que, azedo,

Cuspa lua em decomposição. 
Poema que doa.

Poema que roa.

Poema de não.

Quero versos sem protestos

Versos sem remédio.

Versos sem salvação.

Quero rimas contidas.

Rimas aflitas.

Rimas em ão.

Que é pra compensar que a vida

Entre o escarro e a lambida

Seja lodo e ilusão

(DINHA, 2017, p. 23).

O poema de Maria Nilda de Carvalho Mota, conhecida como Dinha, ${ }^{9}$ permite perceber a possibilidade de a literatura materializar a periferia em imagens poéticas, sem qualquer traço de libelo/ grito reivindicatório, de denúncia, como frequentemente são categorizados os poemas produzidos por mulheres, negras, oriundas da periferia. Não se trata de um poema de resistência, revolucionário, ou, por outro lado, que apresente uma proposta otimista. Ao contrário, é um poema de retirada, construido na realidade, na vida com desespero e tristeza, porque não há saída, exceto o poema que pode compensar e trazer alguma ilusão.

A linguagem da autora, que associa imagem e ritmo em harmônica densidade, resulta no tom pungente do poema, que expressa a vida da periferia, sem tradução ou intermediação de qualquer ordem, simplesmente pelo trabalho com a palavra, que deixa ver o lugar de que "fala" desse eu lírico, sem máscaras ou pretextos, mas com poesia - o que se explicita de forma mais cabal pelas palavras do poeta e ensaísta Octávio Paz:

Ser ambivalente, a palavra poética é plenamente o que é - ritmo, cor, significado - e, ainda assim, é outra coisa: imagem. A poesia converte a pedra, a cor, a palavra e o som em imagens. E essa segunda caracteristica, o fato de serem imagens, e o estranho poder de suscitarem no ouvinte ou no espectador constelações de imagens, transforma em poemas todas as obras de arte (PAZ, 1982, p. 26).

\section{Considerações finais}

A partir das visadas empreendidas aos textos literários selecionados, descortinam-se possibilidades de desconstrução ou de configuração de "estereótipos", na acepção de Hommi Bhabha (1999), que envolvem as figuras "ex-cêntricas" da sociedade (HUTCHEON, 1998). Os escritores que conseguem fazer literatura com o material da violência, da discriminação, do preconceito, do descaso, da exclusão - tão recorrentes nos contextos periféricos -, pode promover o exercício da alteridade, aquele que desacomoda, humaniza, sensibiliza, atuando como "agrimensores do mundo interior das línguas e das fábulas", conforme o crítico quebequense Pierre Ouellet (2013, p. 147).

Movido pela reflexão acerca dos movimentos contemporâneos que levam o homem a viver em deslocamento e desordenamento, Ouellet afirma que a humanidade de hoje vive na iminência de ser expulsa de seus territórios (físicos e/ou interiores), tendo perdido seu senso de fixidez, de proteção ou abrigo, o que inviabiliza a sua possibilidade de ser, de dar sentido à existência (2013, p. 156). Assim, o homem vive na terra de ninguém, privado de espaço e tempo livre, onde sua humanidade poderia se exprimir.

A expressão da humanidade das comunidades periféricas brasileiras se dá pela ação dos escritores que assumem, conforme Ouellet, a condição de "exilio e asilo do homem" (2013, p. 146), daquele que vive sem palavra, com a voz cortada do território interior, hoje mudo. Nesse sentido, o chamamento de Roberto Schwarz, na Apresentação do antológico Os pobres na literatura, por ele organizado ainda 1983, é urgente, atual: "poetas sabem muito sobre muita coisa, inclusive, por exemplo, sobre a pobreza" (2013, p. 7).

\section{Referências}

AQUINO, Marçal. Balaio. In: ANACAONA, Paula (org.). Eu sou favela. São Paulo: Nós, 2015.

BHABHA, Homi. O local da cultura. Belo Horizonte: Editora da Universidade Federal de Minas Gerais, 1999.

\footnotetext{
9 Nascida no estado do Ceará, vive no Parque Bristol, em São Paulo, desde 1979. Sempre ligada aos movimentos sociais de comunidades marginalizadas no Brasil e à sua herança afro-brasileira, hoje é doutora em Letras, professora e poeta. Disponivel em: https:// globaleditora.com.br/autores/biografia/?id=1990. Acesso em: 11 maio 2019
} 
CANDIDO, Antonio. Iniciação à literatura brasileira. Rio de Janeiro: Ouro sobre Azul, 2004.

DINHA. Onde escondemos o ouro. São Paulo: Me Parió Revolução, 2017.

DINHA. Grupo editoria global [online]. [S. L.]: Global Editora, [201?]. Disponivel em: https://globaleditora.com.br/ autores/biografia/?id=1990. Acesso em: 11 maio 2019.

FERRÉZ. Ninguém é inocente em São Paulo. Rio de Janeiro: Objetiva, 2006.

FREIRE, Marcelino. Contos negreiros. Rio de Janeiro: Record, 2005.

HUTCHEON, Linda. Poética do pós-modernismo: história, teoria, ficção. Rio de Janeiro: Imago, 1998.

Imbert, Patrick. Theories of inclusion and exclusion in knowledge-based societies: Canada and the Americas. Ottawa: University of Ottawa, 2008.

JOBIM, Tom. "O morro não tem vez". Letras. Disponivel em: https://www.Letras.mus.br/tom-jobim/49053/. Acesso em: 10 maio 2019

JUNIOR, Jupy. A Rainha Sensual - uma Análise do Fenômeno Xuxa. C-Legenda: Revista do Programa em Pós-graduação em Cinema e Audiovisual da Universidade Federal Fluminense, Rio de Janeiro, v. 04, p. 1-36, 2001. https://doi.org/10.22409/c-legenda.voi04.26123

Candido, Antonio. Literatura e Sociedade, Letra no 2. Rio de Janeiro: Faculdade de Letras da UFRJ, 1984. p. 239.

LANDOWSKI, Eric. Presenças do outro: ensaios de sociossemiótica. São Paulo: Perspectiva, 2002.

LIPOVESTSKY, Gilles. Tempo contra Tempo ou a Sociedade Hipermoderna. In: LIPOVESTSKY, Gilles; CHARLES, Sébastien. Os tempos hipermodernos. Lisboa: Edições 70, 2014.

OUELLET, Pierre. Palavras migratórias. In: HANCIAU, Nubia; DION, Sylvie (org.). A literatura na história a história na literatura: textos canadenses em tradução. Rio Grande: Editora da FURG, 2013.

PATROCÍCINIO, Paulo Roberto Tonani do. Escritos à margem: a presença de autores da periferia na cena literária brasileira. Rio de Janeiro: 7Letras, 2013.

PAZ, Octavio. O arco e a lira. Rio de Janeiro: Nova Fronteira, 1982.

REYES, Alejandro. Vozes dos porões: a literatura periférica/marginal do Brasil. Rio de Janeiro: Aeroplano, 2013.

RIBEIRO, Djamila. O que é lugar de fala? Belo Horizonte: Letramento, 2017.

ROCHA, João César de Castro. A Guerra dos Relatos do Brasil Contemporâneo. Ou: a "dialética da marginalidade". Revista do Pós-Graduação em Letras da Universidade Federal de Santa Maria, Santa Maria, v. 32, p. 23-70, 2006.

SCHOLLHAMER, Karl Erik. Ficção brasileira contemporânea. Rio de Janeiro: Civilização Brasileira, 2009.

SCHWARZ, Roberto (org.). Os pobres na literatura. São Paulo: Brasiliense, 1983.

\section{Maria Tereza Amodeo}

Doutora em Linguistica e Letras pela Pontificia Universidade Católica do Rio Grande do Sul, (PUCRS), em Porto Alegre, RS, Brasil; professora na Pontificia Universidade Católica do Rio Grande do Sul (PUCRS), em Porto Alegre, RS, Brasil.

\section{Endereço para correspondência}

Maria Tereza Amodeo

Pontificia Universidade Católica do Rio Grande do Sul

Av. Ipiranga, 6.681, Prédio 8, sala 401.08

Partenon, 90619900

Porto Alegre, RS, Brasil 